\title{
As micro-utopias de Vanessa De Michelis: território(s) de experimentação sonoro-político para a inclusão e colaboração
}

\author{
Las micro utopías de Vanessa De Michelis: territorio(s) de \\ experimentación sonora-política para la inclusión y colaboración
}

\section{The micro-utopias of Vanessa De Michelis: territories of sonic-political experimentation for inclusion and collaboration}

\author{
Rui Miguel Paiva Chaves ${ }^{1}$ \\ Vanessa De Michelis ${ }^{2}$
}

\begin{abstract}
Resumo
A experimentação musical e sonora brasileira, apesar de algumas excepções pontuais, tende a não promover a existência de espaços institucionais ou informais que façam uma programação afirmativa de artistas femininas e/ ou não-binárias. O artigo, primeiramente faz um percurso reflexivo sobre o processo artístico e ético-político da Vanessa De Michelis focando no seu trabalho de instalação, performance e oferta educativa. Este trabalho encontra paralelos com a ideia de micro-utopia(s) proposta por Nicolas Borriaud. Depois desse momento, o cerne do artigo é uma entrevista realizada em 2016, donde passamos pelo percurso biográfico da artista, a sua abordagem in(disciplinar), mas principalmente o seu esforço em construir uma audição e visibilização de um trabalho que foge às expectativas de gênero associadas ao fazer musical.
\end{abstract}

Palavras-Chave: biografia; crítica institucional; performance não-binária; arte sonora; música experimental

\section{Resumen}

La experimentación musical y sonora brasileña, a pesar de algunas excepciones ocasionales, tiende a no promover la existencia de espacios institucionales o informales que hacen un programa afirmativo de artistas femeninos y/o no binarios. El artículo primero realiza una reflexíon sobre el proceso artístico y ético-político de Vanessa De Michelis enfocándose en su trabajo de instalación, performance y oferta educativa, encontrando paralelos con la ideia de micro-utopía (s) propuesta por Nicolas Borriaud. Después de ese momento, el cerne del artículo es una entrevista realizada en 2016, desde donde recorrimos el camino biográfico de artista, su enfoque in(disciplinario), pero principalmente por su esfuerzo para construir una audición y hacer visible un trabajo que escapa a las expectativas de género asociados ao hacer musical.

Palabras claves: biografía; crítica institucional; performance no-binária; arte sonoro; musica experimental

Abstract

Brazilian musical and sonic experimentation, despite some occasional exceptions, tends not to promote the existence of institutional or informal spaces that make an affirmative curation of female and non-binary artists. In this sense, the article firstly takes a critical look at the artistic and ethical-political process of Vanessa De Michelis, focusing on her installation work, performance and educational offer, whom we think echoes the concept of micro-utopia (s) proposed by Nicolas Borriaud. After this, the core of the article is an interview conducted in 2016, from where we go through the biographical path of the artist, its in(disciplinary) approach,

\footnotetext{
${ }^{1}$ Phd in Music; Universidade Federal da Paraíba, CCTA - Departamento de Artes Visuais, João Pessoa; rui.chaves@gmail.com.

${ }^{2}$ Bacharel em Design e Cultura com ênfase em Design Sonoro; Birbeck, University of London, Reino Unido.
} 
but mainly her effort in building a alternative visibility and listening of a work that escapes the general expectations associated with music made by female artists.

Keywords: biography; institutional critique; non-binary performance; sound art; experimental music

\section{Introdução}

Este texto é pensado entre duas pessoas e escrito entre dois lugares de fala, experiências de vida e posicionamentos epistêmicos. Nesse sentido, a reflexão crítica apropria-se de diferentes formas de escritura, sendo que a voz do crítico aparece na primeira pessoa. Este aporte metodológico resulta da minha experiência de pesquisa ${ }^{3}$ e imersão na cena de arte sonora brasileira que decorreu do trabalho realizado na plataforma online Nendú: um possível arquivo de arte sonora realizado entre 2015-2018 (CHAVES, 2015-2018) e a edição do livro Making It Heard: A History of Brazilian Sound Art (CHAVES; IAZZETTA, 2019). A criação da plataforma teve como base os seguintes objetivos: "1) a criação de um 'espaço' de disseminação e conhecimento da prática local; 2) o instigar de conversas ou processos de documentação que ilustram processos individuais de criação" (CHAVES, 2015-2018).

Tanto Nendú como Making it Heard foram iniciativas orientadas para a constituição de uma reflexão multi-vocal sobre a relação entre arte sonora e o quotidiano político, sonoro, social e urbano local. Um processo necessariamente baseado na análise e observação do discurso e práxis no Brasil, havendo uma tentativa de distância crítica do cânone europeu e norte-americano, tentando encontrar paralelismos históricos em vez de histórias singulares engessadas numa episteme dominante ${ }^{4}$.

Neste caso, o texto parte da constatação de alguns factores. A pesquisadora Tânia Mello Neiva em Engaged Sonorities: Politics and Gender in the Work of Vanessa De Michelis (2019, p.229-248) descreve um panorama de música experimental e arte sonora, que ao mesmo tempo que tem dificuldades de implantação e sustentação no tecido cultural brasileiro, também demonstra uma falta de representatividade dos seus atores. Existem fatores endógenos à sociedade brasileira, como a dificuldade de acesso ao ensino superior onde alguma formação nesta área é feita. Para além disso, existe também uma associação entre música e tecnologia, ligada a uma ideia de inventividade, que tende a reproduzir padrões de

3 Projeto de pós-doutorado financiado pela Fundação de Amparo à Pesquisa de São Paulo (2014-15978/9)

4 Por exemplo, na historiografia contemporânea de cariz anglófono e eurocêntrico, celebra-se a influência do John Cage na diluição das fronteiras entre o quotidiano e o fazer artístico. No caso do Brasil, encontramos com igual importância esse tipo de manobra no trabalho do Hélio Oiticica (no caso dos seus parangolés). 
exclusão/invisibilização. Estes são@s outr@s da música experimental/arte sonora, como é o caso das mulheres (NEIVA, 2019, p.229-230). Como um dos factores, Mello Neiva descreve que isso se deve a uma estereotipização do papel da mulher na música (NEIVA,2019,p.231). Nesse sentido, o movimento do artigo passa por uma breve descrição do trabalho da De Michelis, acabando numa entrevista que foca no percurso biográfico desta e a forma como o seu trabalho artístico foi cada vez mais investigando os binarismos inerentes (masculino/feminino) existentes no campo da música experimental, ao mesmo tempo que foi experimentando com novas formas de estar com o público. Quero aproveitar também para fazer uma pequena interjeição sobre a forma posicional como vou usar os termos música experimental, arte sonora e arte contemporânea. Esta abordagem deve-se à óbvia contaminação poética-conceitual entre essas diferentes terminologias.

\section{Vanessa de Michelis}

Vanessa De Michelis (1983, Belo Horizonte) é uma artista que trabalha desde 2009 como compositora, artista sonora e educadora. O seu trabalho é uma jornada por 'lugares' (através da experimentação com recursos instrumentais, eletroacústicos, gravações e manipulação de materiais) que resultam em performances audiovisuais, instalações, peças sonoras e trilhas para cinema. Teve trabalhos performados e transmitidos no Brasil, China, Chile, Colômbia, Canadá, EUA, Alemanha, França, Suécia e Inglaterra. Destaca-se a sua presença em festivais, residências, eventos de arte contemporânea e música experimental: Arte.Mov Brasil, FILE Hypersonica, 43ํ Festival de Brasília (prémio de melhor trilha sonora, LABMIS, Paço das Artes (São Paulo), Museu de Arte Moderna de Salvador, ou o Palácio das Artes

Horizonte).

A sua prática é apoiada por uma ética feminista que a faz questionar o privilégio simbólico e logístico decorrente do fazer artístico: a necessidade de ter espaço/tempo/dinheiro. Num blogue criado em 2016 (human infestation), a De Michelis em TPM anti-criativa (2016) expõe a dificuldade de uma suposta necessária alienação quando uma existência é marcada, não só por uma possível transformação hormonal, mas também por processos de subjetivação emocionais e afetivos que nos ligam às preocupações do quotidiano:

Criar arte/música não é algo que se faz em 5 minutos, durante um cigarro, depois de um DR relacional, no intervalo de almoço do seu trabalho, enquanto se limpa as fezes do cachorro, do gato, do bebê, da própria bunda. Não há espaço enquanto você se preocupa com as contas da sua mãe, com a saúde da sua tia, com o assassinato do 
travesti noite passada, como as pessoas te olham quando você existe na rua, com o dinheiro da semana que vem, com cozinhar algo equilibrado, com as obras de viadutos superfaturadas, com responder o messenger, ruminar o amor que você sentiu noite passada, ouvir os problemas dos amigos na mesa da cozinha, dobrar as roupas que se rebelam contra o feng shui (De Michelis, 2016).

É desta 'posição' que eu escuto o trabalho da artista. Neste âmbito, a Mello Neiva, no artigo já mencionado descreve o trabalho da artista como uma:

afirmação política-ideológica do eu, que insiste na sua identificação de gênero nãobinário; a sua sexualidade lésbica, a suas preocupações com o ambiente e com as condição de vida com as pessoas marginalizadas (pobres, racializadas, LGBTQI e outras); a sua preocupação com a exploração e opressão causadas pelo capitalismo, sexismo, LGBTQI-fobia e racismo ${ }^{5}$ (NEIVA, 2019, p.234).

Esta "afirmação" (ibid.) acontece dentro de uma relação crítica com o cânone da música experimental, arte sonora e arte contemporânea, para além de uma necessidade decorrente de estabelecer novas formas de 'estar com' e partilhar o seu trabalho. Numa entrevista dada a Juliana Gontijo em 2013 para o livro Distopias Tecnológicas, a De Michelis inclusive refere uma certa preferência pelo trabalho das oficinas em vez de "fazer um trabalho específico, que terminaria sendo chamado de objeto artístico ou instalação em algum tipo de exposição, cujo potencial do público é resumido a um espectador passivo ou quiçá interativo" (GONTIJO, 2013, p.211). Isto é aliado a uma visão de "empoderamento" (ibid., p.212) e de ser mais "gratificante" (ibdi., p.212) para esta :

trabalhar com formas que proporcionem menos hierarquias, ainda que utilizem temáticas ou processos considerados artísticos. Acho que a obra, muitas vezes, é um meio para um diálogo e para uma transformação pessoal que transbordam o formato de apresentação expositiva, que privilegia a obra como um fim. Portanto, faz com que por meio da "visibilização" da obra seja gerada uma "invisibilização", silenciamento e hierarquização da relação entre o público e a figura do artista. (Ibid., p.212)

É dessa relação entre arte e vida, observação do privilégio do fazer artístico, acompanhada de uma necessidade de desestabilizar as hierarquias estabelecidas entre o

\footnotetext{
5 Minha tradução de: political-ideological affirmation of the self, which insists on her non-binary gender identification; her lesbian sexuality; her concerns with the environment and with the living conditions of marginalized people (poor, racialized, LGBTQI, and others); her concerns about exploitation and oppression caused by capitalism, sexism, LGBTQI-phobia, and racism
} 
"público e a figura do artista" (Ibid.) que irei analisar brevemente os trabalhos Interlúdio e A Tensão como micro-utopias. Essa terminologia, desenvolvida por Nicolas Bourriaud (em Relational Aesthetics) é descrita como a criação de novas formas de convivialidade e encontro entre artista-audiência (fugindo ao ethos modernista da novidade) promovendo "construções temporárias e nomádicas nos quais o artista modela e dissemina situações desconcertantes" 6 (BORRIAUD, 2009, p.31). Apesar de a descrição crítica de ambos os trabalhos ser breve, eu considero que a análise feita, permite ao leitor(a) descobrir algumas das abordagens do trabalho da De Michelis e compreender melhor a direção que a nossa conversa toma durante a $\begin{array}{llll}\text { entrevista } & \text { (incluindo temas encados). }\end{array}$

\section{Interlúdio}

No documentário Interlúdio (realizado por Gabraz Sanna, 2016), sobre a banda póspunk Post (Vanessa de Michelis e Jiulian Gonçalves) vemos corpos a ocupar e viver lugares, a realizar gravações de campo $^{7}$, a meditar, a conviver, a existir em ternura e companheirismo, no que parece ser um relato documental pela busca de novas "paisagens sonoras" (Sanna, 2016). Esta sequência de ações levanta questões sobre o fazer sonoro ecoando o conceito de musicking do musicólogo Christopher Small, donde a música é indelevelmente associada à sua prática social e convenções performativas:

Eu propus a seguinte definição: fazer música é participar, em qualquer capacidade, numa performance musical, quer por performando, escutando, ensaiando/praticando, fornecendo material para uma performance (o que é chamado de composição) ou dançando. Por vezes, devemos estender esta definição à pessoa que recebe os bilhetes na entrada ou aos homens que mudam o piano ou a bateria (...) à equipe de limpeza que limpa o espaço após toda a gente ter ido embora. Estes também contribuem para a natureza do evento que designamos de performance musical ${ }^{8}$ (SMALL, 1998, p.9).

\footnotetext{
6 Minha tradução de "temporary and nomadic constructions whereby the artist models and disseminates disconcerting situations"

$7 \quad$ O ato de realizar gravações áudio em locais exteriores, fora da situação normal de 'estúdio'.

$8 \quad$ Minha tradução de: I have proposed this definition: To music is to take part, in any capacity, in a musical performance, whether by performing, by listening, by rehearsing or practicing, by providing material for performance (what is called composing), or by dancing. We might at times even extend its meaning to what the person is doing who takes the tickets at the door or the hefty men who shift the piano and the drums (...) or the cleaners who clean up after everyone else has gone. They, too, are all contributing to the nature of the event that is a musical performance
} 
Interlúdio é um ato de generosidade, uma vez que carne e osso queer, cuja audibilidade está em constante risco de violência física e simbólica, demonstra que a escuta e o fazer a música em conjunto podem constituir outras possibilidades/experimentações no amar e amor fora do que tradicionalmente consideramos ser a intimidade convencional.

\section{A Tensão}

Em A Tensão, a artista explorou diferentes aparelhos receptores de ondas electromagnéticas (como rádios portatéis), apostando em gestos subtis do ponto de vista cinético e sônico de forma a deconstruir algumas das estratégias utilizadas no mundo da noise music, que é frequentemente associada a performances com amplitudes sonoras exageradas (Mello Neiva, 2019, p.237). Em 2015, eu tive a oportunidade de assistir à performance deste trabalho no FIME $^{9}$ (onde a De Michelis foi acompanhada pela Jiulian Gonçalves). O aparato cênico e tecnológico utilizado contrastou com a maioria das performances que apostaram em gesturalidades exageradas, e em corpos posicionados de forma hierárquica na sua relação com o público. No trabalho A Tensão $o^{10}$, a De Michelis ofereceu ao ouvinte outras formas de escuta e de estar, talvez enunciando o constante respeito que a artista tem pelo espaço e tempo de cada um. Em A Tensão, dois corpos se sentaram no chão perto da audiência, da barreira por vezes insuportável de som e parafernália tecnológica, duas presenças contrastam na execução de movimentos finos em objetos do quotidiano. Nessa performance, um diálogo emerge entre ouvinte-performer, uma conexão intersubjectiva que não advém de uma experiência préconcebida num feminino idealizado, mas de um possibilitar a um todo uma subversão dos aparelhos sônicos que se encontram na nossa proximidade.

\footnotetext{
$9 \quad$ Festival Internacional de Música Experimental (21 a 31 de Julho de 2015) https://www.youtube.com/watch?v=T8Lp1WUgMOE
}

10 É possível ouvir um pequeno excerto da performance em: https://vimeo.com/120327987 


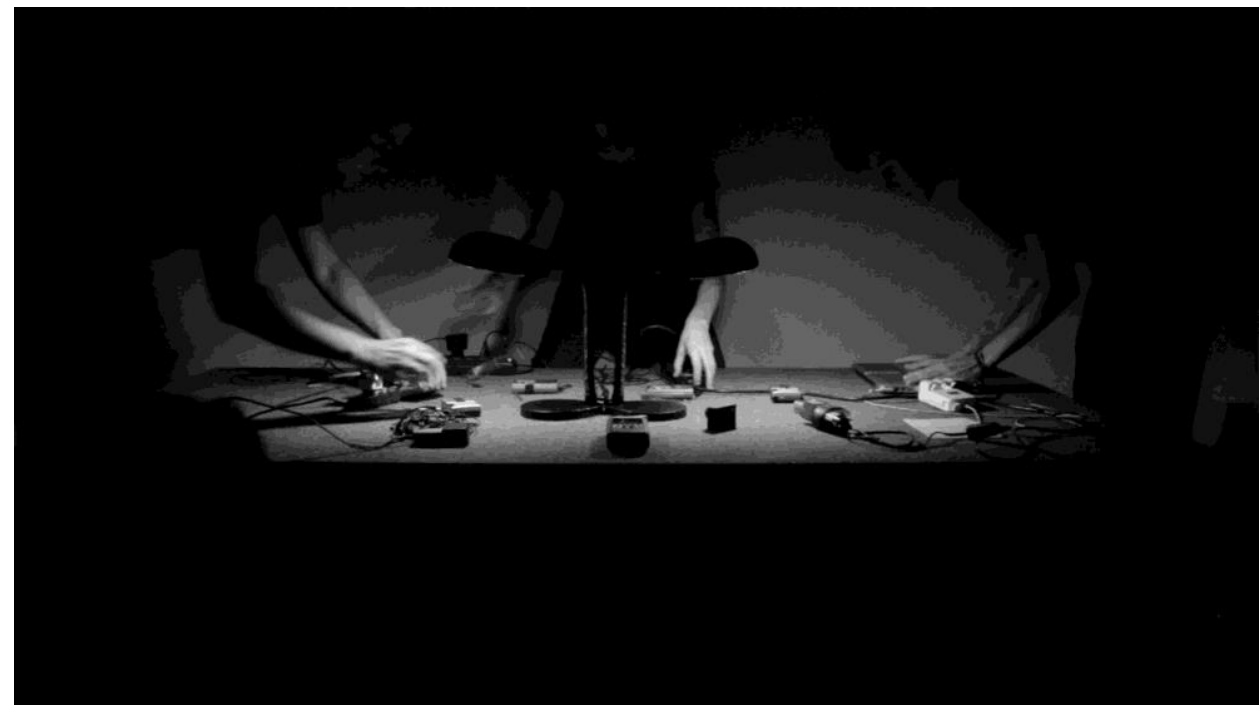

Fotografia 1- A Tensão. Performance na Red Bull Station: Herbert Baioco, Vanessa de Michelis, Jiulian Gonçalves (São Paulo, 2015). Fonte: Brunella Martina.

\section{Entrevista}

Com a ideia de "micro-utopias", Borriaud ecoava a proposta de Félix Guattari (em Molecular Revolution: Psychiatry and Politics) para diferentes formas de micro-política, que em vez de grandes mudanças estruturais do sistema político, podiam passar por pequenos momentos de resistência "molecular". Isto podia-se concretizar na organização de creches numa universidade (GUATTARI, 1984, p.31), ou no caso da De Michelis, com a organização de atividades formativas ${ }^{11}$ para mulheres lésbicas e não-lésbicas adquirirem conhecimentos na área de música-tecnologia e arte sonora (De Michelis, 2015a), ou então na criação de performances ou instalações que ofereçam um espaço de contato entre diferentes milieus políticos e estéticos fora de um regime hegemônico hetero-normativo.

Como já descrevi anteriormente em Making Oneself Heard in Public, through Art and in Sound-Based Scholarship (CHAVES, 2019, p.48 ) considero que este trabalho da De Michelis, em tempos de divisão, sectarismo e autoritarismo, procura engajar com uma das estratégias que percorre o trabalho de alguns artistas da arte sonora brasileira, que é a possibilidade de estabelecer "conversas" e outras formas de sociabilidade, uma vez que o sônico e o seu fazer podem engendrar formas de coexistência, ou espaços seguros para diferentes grupos que são consistentemente invisibilizados (Ibid.). A entrevista que se segue (realizada no dia 10/04/2016 no SESC Ipiranga, em São Paulo) percorre algum desses temas,

11 Esses espaços 'minimamente seguros' têm sido um dos focos da De Michelis enquanto educadora, nomeadamente no que diz respeito à organização de oficinas dedicadas à montagem de palco e electrónica DIY (De Michelis, 2015a) 
finalizando na sua crescente conscientização relativamente ao seu papel de compositora/performer no circuito de música experimental brasileiro.

Rui Chaves: Quando estávamos em contato, tu falaste que o teu trabalho tem uma diversidade enorme (sendo que era isso mesmo que me interessava no teu trabalho). Achas que essa experimentação, esse ato de viver, acaba por ditar essa diversidade no teu trabalho? Isso de trabalhar com diversas coisas, achas que tem a ver com essa necessidade de experimentação? O fato de não estar tão fixada numa ideia de identidade como artista e dizer 'sou isso'...

Vanessa de Michelis: É... isso é um ponto a favor do trabalho por um lado, porque quem valoriza esse tipo de diversidade, de abordagem, é um prato cheio pra interlocuções, pra espaços híbridos, agora, por outro lado, é uma coisa que é um pouco complicada pra mim, porque encontrar essa linha que permeia tudo o que eu acho que é o meu trabalho atual, tentar entender um discurso que permeie todos esses trabalhos, mas que seja um discurso que se aprofunde também neles. Não uma linha superficial que conecte todos, porque isso também pode enfraquecer um pouco, pode parecer que a pessoa tá em várias coisas e ela não se envolve profundamente com nada, então tem esses dois lados, porque três linhas que são muito claras e que permeiam todos os trabalhos são... a primeira delas seria, hoje em dia, depois de quase dez anos analisando todas essas vertentes, seria o gênero, porque durante um período inicial da carreira eu era sempre a única mulher nos espaços, nas aulas de música, nos cursos de instrumentos ou cursos de eletrônica, todas as formações, oficinas, qualquer tipo de formação, os assuntos do meu interesse eu sempre era a única mulher... e hoje isso se inverteu de uma maneira que é muito bonita pra mim, porque a maioria desses lugares hoje em dia são espaços praticamente ou exclusivamente de mulheres, ou mistos com um foco absurdo na equidade de gênero e onde as mulheres são protagonistas e não invisibilizadas e minoria, então isso eu posso dizer que em 10 anos mudou bastante e eu posso dizer que eu saí de um lugar de observação, onde eu trabalhei bastante pra transformar (....) e parti pra um lugar de protagonismo nessas cenas e hoje eu não só protagonizo algumas dessas cenas, como também faço parte de redes que trabalham na formação de outras mulheres e de atenção em todos os espaços, pra que as mulheres estejam presentes de maneira igualitária em número pelo menos, até a gente passar pra outras questões delas se sentirem a vontade de estar presentes ali de uma maneira geral, então isso é uma linha, o gênero, e estar presente em espaços femininos, feministas, ou exclusivamente de mulheres e não só mulheres, mas mulheres lésbicas, pessoas trans, as dissidências de identidade, então isso se liga novamente à experimentação, por exemplo (...) existe uma questão com a experimentação que é a 
diferença entre o experimental e o experimento, então se você chega pela primeira vez pra trabalhar numa coisa, então você tá numa zona de experimentação, mas se você trabalha com essa coisa há muito tempo, aquilo não é mais uma experimentação, é um experimento, que você começa a aplicar metodologias específicas e ter um desenvolvimento daquele experimento, a ponto de você não poder mais falar que aquilo é uma experimentação, porque uma experimentação envolve um objeto de estudo que é novo pra você de alguma maneira; depois que você passa anos experimentando com circuito, por exemplo, você não pode mais falar que é uma experimentação, então eu acho que muita gente se perde um pouco nessa estética do experimental e usa ela como desculpa pra permanecer numa superfície, que não é o meu caso, mas porque o meu interesse é com experimentar com os objetos e com os espaços e com as pessoas, então às vezes eu chego num lugar onde alguns dos pilares dessa estrutura se esgota e perde o sentido de se estar ali, então...

RC: Eu acho que essa dimensão do espaço e das pessoas é muito claro no teu trabalho, seja através das caminhadas sonoras (DE MICHELIS, 2011) que tu fizeste....

VM: Sim.... entre os dispositivos, os espaços e as pessoas... Bom, então acho que é um pouco isso... e os meus trabalhos mais atuais em relação a performances sonoras e a construção de instalações ou objetos, que você viu um deles específico que foi A Tensão, né? Mas A Tensão é um de uma série de 4 trabalhos (...) que eu desenvolvi durante a residência na Red Bull em janeiro, fevereiro e março de 2015 (DE MICHELIS, 2015b) e todos esses trabalhos têm uma característica específica que é um cuidado bem grande com a apresentação (...) a fonte sonora como um experimento metodológico de investigação de um som, um objeto específico, então isso me aproximou um pouco da música contemporânea e da performance, o que foi um salto interessante pra mim, porque eu nuca tive interesse antes de me aproximar mais da música contemporânea, por exemplo, em termos de ter esse cuidado com a gestualidade ${ }^{12}$, mas ao mesmo tempo, como eu tinha esgotado a música experimental em relação a redes e a espaços, porque eu me sentia muito sozinha nesses espaços, porque eu não me identificava basicamente com as pessoas e com as propostas delas de vida...

RC: Tu achas que... há pessoas que descrevem particularmente na noise music (...) uma espécie de machismo, uma espécie de virilidade, uber virilidade (...) achas que isso também tem existido na cena local?

12 Um exemplo disso é a peça Gesto Sonoro - Sound Gesture (performance e instalação), (De Michelis, 2015c) 
VM: Eu fiz minha graduação em design e anteriormente a isso, eu sempre estudei música, mas de um jeito informal, eu estudei guitarra, estudei piano, estudei bateria, então eu sempre tive um interesse múltiplo, mas a minha família toda é de músicos, tenho uns tios maestros, mas também música popular, chorinho, todo mundo toca chorinho e quando eu era criança era esperado de mim que eu fosse um prodígio, já de nascença, então todo mundo sentava pra tocar chorinho numa roda gigante de família e eu com 5 anos batendo no pandeiro de qualquer jeito, porque eu tinha 5 anos, eu não sabia tocar e era meio uma frustração que eu não tinha nascido já tocando, e aí eu meio que sempre toquei, mas me afastei um pouco dessas expectativas da família, mesmo porque o meu interesse era punk rock, era música eletrônica e isso era bem marginal, então todo mundo já tirou essas expectativas falando 'não, ela é de outra coisa'; eu tive várias bandas nesse período e quando eu estava na faculdade de design eu entrei em contato com design sonoro, então eu tive um professor de design sonoro que estava começando a trabalhar com software que se chamava EyesWeb ${ }^{13}$ e esse software é um precursor do PD e do $\operatorname{Max}^{14}$ e ele era desenvolvido num laboratório na Itália e meu professor estava pesquisando isso, então eu fiquei um ano fazendo as disciplinas de design sonoro (...) e me candidatei pra ser a monitora da disciplina, aí virei a monitora da disciplina e esse professor foi embora fazer o doutorado dele em Ghent na Bélgica e entrou um poeta, um artista que trabalhava com poesia sonora e com poesia falada e com som, então esse artista, que é um poeta muito importante em Belo Horizonte chamado Ricardo Aleixo ${ }^{15}$ (...) que trazia outra abordagem, de poesia concreta (...) começou a trabalhar muito mais poéticas sonoras e performances, a trazer a voz e a usar muito o estúdio, porque nessa época construiuse um estúdio, pra disciplina de design sonoro dentro da faculdade, e eu comecei um projeto junto com esse professor, o Ricardo Aleixo, da gente criar um núcleo de design sonoro dentro da faculdade (...) a gente realizava projetos nossos, basicamente, lá (pausa), então nós criamos o núcleo de design sonoro e o laboratório e ninguém utilizava o estúdio, exceto nós, pros nossos fins particulares e a faculdade de moda, que criava trilhas sonoras pros desfiles lá, então nessa época, eu fiz cursos de home studio e de produção musical, pra poder trabalhar

\footnotetext{
13 Software que permite gerar interações (através da captura de imagem) entre performers e diferentes mídia (video, som, luz).

http://www.infomus.org/eyesweb_ita.php

14 O PD e o Max são linguagens de programação visual que permitem gerar interações multimodais, mas também funcionar como plataformas de processamento sonoro e composição musical.

15 https://enciclopedia.itaucultural.org.br/pessoa3623/ricardo-aleixo
} 
com gravação, mixagem, masterização e mesas, microfones, cabos, então eu me profissionalizei bastante em relação a essa área técnica do áudio...

RC: Que na altura devia ter só homens também, né?! Nesses cursos...

VM: Só homens! Só! E só homens roqueiros, porque ninguém sabia direito o que era foley, fazer efeitos sonoros, e o estúdio de design sonoro funcionava basicamente pra sonoplastia, pra disciplina de vídeo e design e pra trilha sonora, pra disciplina da moda, aí a hora que passou essa fase, quando eu me formei eu fiz uma monografia sobre design sonoro, que foi a primeira monografia de Belo Horizonte, de Minas Gerais e talvez até do Brasil, não sei, de graduação sobre design sonoro, porque não existia design sonoro nessa época, ninguém sabia o que era, existia publicidade, existia engenharia de áudio e existia música e a faculdade que eu estudei era a única que tinha design sonoro no Brasil, dentro da carga horária; um pouco antes disso, durante a faculdade, eu fiz outra faculdade paralela, de artes plásticas, e eu estudei dois anos e meio e perdi completamente a paciência com as disciplinas práticas, eu fazia só as teóricas (...) e tinha uma disciplina teórica que a gente estava estudando um livro do Kandinsky, que é o Ponto e linha sobre plano (2012), que é um livro clássico das artes plásticas e do design, que ele fala basicamente como o ponto é estrutura básica de formação da imagem e de direcionamento do olhar e como você mover esse ponto numa tela, como você movê-lo bidimensionalmente e tridimensionalmente através da perspectiva, e como que você, gerando mais e mais pontos, você começa a ter noção de linha, de espaço, disso, daquilo, então eu fiz uma gravação de uma leitura de um trecho desse livro e todos os exemplos eu fazia sonoramente, então assim, o ponto na tela, no meio era um som centralizado, o ponto se movia pra esquerda, eu trabalhava o panorama, aí vários pontos eu texturizava a voz pra fazer isso, gerava perspectiva, afastava o som com reverb...

RC: Era um trabalho multi-canal ${ }^{16}$ ?

VM: Trabalho multicanal! Então isso foi bem legal e quando eu mostrei isso pra minha professora, ela praticamente chorou, porque era muito fora da caixinha, então essa professora ficou tão feliz que ela organizou uma mostra, um evento na faculdade, pra que eu apresentasse essa peça no teatro da faculdade, então ela chamou todos os períodos, todas as turmas, ficou

16 Expressão utilizada para descrever a utilização de várias caixas sonoras emitindo cada uma, uma fonte sonora distinta. 
todo mundo sentado, umas 100 pessoas, e a gente apresentou em quatro canais, que eu chamei um amigo pra me ajudar na difusão...

\section{RC: Você fez a difusão em tempo real ${ }^{17}$ ?}

VM: É! Mas a peça era gravada, eu não fui falando, né... os canais. Então esses foram exercícios que são muito importantes pra minha formação, porque eu tava inventando uma coisa pra mim, no meu mundo, nas minhas referências essas coisas não existiam...

RC: Isso foi antes de ter contato com artistas que desenvolviam esse tipo de trabalho? Ou foi uma coisa que na altura, já estavas a pesquisar e já tinhas um conhecimento da prática das coisas que existiam semelhantes ao que estavas a fazer?

VM: Outra coisa importante pra dizer é que durante o núcleo do laboratório de design sonoro, eu fiz uma bibliografia, que teoricamente seria pra faculdade, mas a faculdade não quis comprar os livros, aí eu fui comprando, eu mesma, uma bibliografia pro laboratório de design sonoro, e essa bibliografia era constituída de livros que são fundamentais na arte sonora, mas eu não sabia, eu ia comprando o que eu achava legal (...) e eu fiz umas viagens também, então era uma bibliografia que tinha vários questionamentos sobre escuta, sobre arte sonora, sobre paisagem sonora, mas eu não conseguia linkar as coisas, eu não me via como uma artista nem nada, até então, pra mim, eu estava experimentando nas artes plásticas, ou fazendo design sonoro (...) eu tinha abandonado os instrumentos, porque eu não conseguia achar pessoas pra tocar comigo coisas que eu queria tocar, e todas as pessoas ao meu redor eram homens e ou virtuosos da música erudita ou virtuosos do punk rock, e aí eu fui pra música eletrônica (...) eu fui a primeira DJ mulher de BH também, e isso tem mais de oito anos, bastante tempo, e aí eu toquei durante dois, três anos, mas esse fim dessa temporada de mais ou menos dois, três anos, eu já estava me formando na faculdade, eu já pensava bastante em design sonoro, em experimentação sonora, e eu comecei a experimentar bastante na pista e a pista esvaziou (risos), não rolava, não rolava de misturar circuit-bending com os vinis... antes eu era uma DJ que fechava a noite e eu passei a ser uma DJ que abria (...) o beat ficava mais slow, slow beat, ambiências, até que o beat desapareceu e aquele não era mais o lugar pra mim, então essa série de coisas é bem engraçada (risos) (...) eu tenho a sensação que é porque essas pessoas têm a experimentação como um filtro aplicado especificamente a uma área da

17 Quando o compositor, ou um técnico decide em tempo real para onde cada faixa sonora é direccionada (utilizando um sistema de caixas sonoras). 
vida delas, não é uma condição intrínseca da existência dela no mundo, experimentar, é uma ferramenta em uma área da vida que ela usa aquilo, ela não precisa da experimentação pra navegar na vida... sou lésbica, latino-americana, vivi em Belo Horizonte, no Brasil, onde as coisas, naquela época, no início da minha juventude, eram muito ruins pras mulheres, então a experimentação pra mim sempre foi uma condição, eu sempre era a menina que queria jogar futebol e ficar sem camisa e brincar suja na grama, então experimentações num nível muito básico de existência... se eu fosse cientista ou astrônoma, provavelmente eu estaria experimentando também nessas áreas, mas a condição específica do som pra mim era o poder que ele tinha de mover alguma coisa na estrutura cerebral das pessoas que nunca tinham sido movidas, então realmente eram hiperlinks nos cérebros das pessoas que destravavam algum tipo de bloqueio, e isso pra mim é o mais interessante, como o som transcende os links racionais que você faz de leitura do mundo e de compreensão das coisas.

RC: Nas conversas que eu tenho tido com os artistas, há uma coisa que pra mim fica claro, que tem a ver com o tempo, da pessoa ter atenção e encontrar uma presença na escuta, porque se você faz uma proposta de uma performance, a pessoa está lá, temporalmente, do inicio ao fim, e dar esse tipo de atenção é um tipo de percepção que é diferente a tantas outras experiências, acho que essa percepção, essa condição da presença é que tem essa coisa super primal, super...

VM: É, total! É meditativo, mas é primitivo ao mesmo tempo, então esse poder é uma coisa que me move e talvez, uma questão de estar um pouco à margem da música contemporânea ou até da música experimental, porque pra mim não faz tanto sentido apresentar algumas propostas de escuta ou ideia pra pessoas que não têm uma abertura pra uma escuta mais mágica, então assim, quando a escuta se torna um lugar completamente territorializado, que a pessoa já não consegue sentir ou propor afetos com aquilo, se relacionar com aquilo de uma maneira afetuosa, pra mim já não interessa mais, porque daí fica uma coisa extremamente técnica e eu tenho apreciação técnica, claro, mas eu me interesso muito mais pela parte ritualística, pela parte afetiva, pela dimensão relacional, por você trocar com as pessoas que estão escutando ou soando ali... acho que é isso, em relação a essa trajetória. Dando um pulo agora, em relação à proposta da $A$ Tensão, que foi a peça que você viu no FIME, foi a primeira vez em muito tempo que eu me senti à vontade pra estar no meio da música experimental de novo, de uma maneira mais formal, porque eu senti que eu estava investigando uma coisa com essa peça, que era um afeto novo, que tinha um potencial naquela peça de subverter algumas estruturas na música experimental aqui, que se tornaram 
muito rígidas, por exemplo, o volume, as relações de poder, então, por exemplo, existe uma certa expectativa ali ao longo de todo esse tempo, pelo menos pra mim, enquanto mulher, que pelo fato de você ser mulher, você sempre tem que ir além em relação a algumas das coisas pra você ser reconhecida, então você tem que ser melhor no seu instrumento do que todos os homens pra você ser reconhecida, ou se você faz noise, você tem que fazer o noise mais radical, mais extremo, então você tem que ir mais além, porque se você faz musica experimental mais baseada num discurso de texturas, de ruídos, disso, daquilo, você corre o risco de ser mais delicada, e se você for delicada, é óbvio que é uma escolha de mulher, então o seu gênero ele sempre tá jogando ali, pesando, porque um homem tem a liberdade de fazer delicado ou... agora, mulher, se ela faz delicado, ela faz delicado porque ela é mulher, e se ela faz muito radical e muito extremo, ela deve ser lésbica, ou ela deve ser gótica, alguma coisa estranha ela deve ser... e eu me lembro, no caso das bandas, os homens têm banda de surf music, banda de forró, banda de metal, as mulheres, elas têm uma banda de mulheres, então vai tocar uma banda ali 'ah, vai tocar uma banda de metal, uma de rock e uma de meninas' (risos), então é uma armadilha que muitas mulheres caem, porque é uma das únicas ferramentas que é dada pra você, você tem que ser mais inteligente ou você tem que ser melhor, e na verdade não só das mulheres, mas de qualquer marginalidade, se a pessoa é negra, pra ela ser legitimada à vezes ela sente isso, porque ela tem que provar pra todo mundo que ela é inteligente e que ela não tá ali só porque ela entrou pela cota, então (...) de uns dois anos pra cá, eu decidi parar de achar que eu tinha que fazer o noise mais extremo, que eu tinha que fazer o sintetizador mais legal ou que eu tinha que ser a melhor guitarrista, porque eu era mulher, então...

RC: Mas isso advém do machismo que existe na cena musical? Não só o machismo, mas também certas ideias rígidas a cerca do que é virilidade, quem pode ser viril, quem não pode ser viril, o que é masculinidade, o que é feminilidade, ideias super rígidas do que as coisas podem ser...

VM: Isso! E pra facilitar as coisas (...) podem ser pessoas que não estão muito familiarizadas com esses termos, mas eu acho que o machismo e o sexismo e a rigidez em relação ao que é masculino e feminino, eu queria pensar nisso assim: o machismo como a cultura do machismo, não o machismo como os homens, então vamos falar 'a cultura do machismo', porque o machismo é uma cultura cujos representantes, quase que naturalmente, são os homens, mas também as mulheres podem ser machistas, mas eu não quero falar isso, eu quero falar a cultura do machismo, porque essa discussão 'ai, as mulheres também são machistas, os 
negros também são racistas' é uma discussão ridícula, é você confundir a força do opressor com a resistência do oprimido e a confusão entre esses papeis, então... enfim, a cultura do machismo é a responsável por isso, mas a cultura do machismo só existe por causa da definição de alguns papeis, das identidades de gênero... muitos filósofos e filósofas hoje falam que o feminismo é a corrente filosófica mais importante da atualidade, junto com os estudos de gênero, porque essas vertentes são as únicas realmente capazes de transformar o pensamento e a cultura hoje.

RC: Nesse sentido, aquilo que tu propões ser a coisa mais distante possível de uma escuta reduzida $^{18}$, porque é uma escuta política também, tem uma coisa de ritual, imersiva, mas também é uma escuta que é política.

VM: É uma escuta política. Mas eu não tenho nada contra uma escuta reduzida, inclusive eu acho fundamental, eu acho que a diversidade, a escuta rizomática vai passar pela reduzida, depois ela vai pra corporal... então eu acho que o inter-relacionamento de todas essas coisas, ao invés da qual disputa de qual é a mais poderosa e a melhor... mas ao mesmo tempo eu entendo que a medida que cada uma vai surgindo, ela surge muito pela força de oposição em relação a alguma coisa que aconteceu ali que você precisa gerar um contraponto, mas quando o tempo passa, a gente não precisa mais... mas é claro que um trabalho específico que investiga a escuta reduzida, pode ser um trabalho maravilhoso, mas eu acho que alguns dos problemas são que alguns têm mais valor do que outro, e o FIME um festival muito importante, porque eu acho que pela primeira vez no Brasil, na história da música experimental, houve uma distribuição do poder entre os curadores, entre os discursos, entre as diferentes linguagens, tinham diferentes vertentes da música experimental e todo mundo assistindo, dando o devido valor às diferentes vertentes da música experimental... quer dizer, nem todo mundo dando o devido valor, mas era sugerido dar-se o devido valor a todas as propostas, mas existem pessoas que vão favorecer o erudito, o contemporâneo, a investigação instrumental x, aí você chega lá com outra coisa... mas o que foi bacana da minha peça foi que pessoas de todos os universos vieram falar comigo, surpreendentemente ela atingiu as pessoas da música erudita, que se satisfizeram com o cuidado, com a gestualidade e com a

18 A escuta reduzida ( ou écoute reduite) é desenvolvido pelo compositor Pierre Schaeffer em Traité des objets musicaux: essai interdisciplines (1966). Igor Reyner (em Pierre Schaeffer e a sua teoria da escuta) descreve a escuta reduzida como algo que "permite ao ouvinte se perceber ouvindo, reconstruir sua própria escuta e, através dessa consciência (num jogo de novas intenções), pavimentar um caminho para a criação, musical ou não" (REYNER, 2011, p.90). 
apresentação formal de ter movimentos e partituras, então isso satisfez as pessoas (risos); as pessoas do noise gostaram da ideia da escuta minimalista do noise eletromagnético, então foi uma sacada muito importante pra mim porque eu queria fazer um statement contra essa estrutura de poder da música experimental que é a opressão sonora, a massividade do volume e sobretudo em relação a mim mesma, porque eu achava que eu precisava investigar esse caminho pra ser ouvida e que eu precisava do volume, mas depois que eu me mudei pra São Paulo, eu me cansei absolutamente do volume, o volume me incomoda absurdamente, depois que eu me mudei pra cá eu parei de estudar noise e fui estudar piano, porque eu não aguentava mais a artificialidade dos sons, a industrialidade dos sons, o volume, a massa sonora constante, a falação, as máquinas, então pra mim essa escuta reduzida quanto ao volume era essencial, criar uma peça cuja atenção, a escuta fosse uma escolha da pessoa e não um automatismo, que você senta num auditório e automaticamente todo mundo vai ser inundado por aquela massa sonora e aí às vezes você nem consegue se colocar no estado da escuta, porque ela já tá tão dada que você não entra naquela transdução, o transe ali do fantasminha que a gente tava falando, o espaço do insight ali, que é um meio termo entre a atenção, a dúvida, o pensamento, o afeto, o medo, porque estar numa sala com o volume baixinho, as pessoas ficam com medo de não escutar também, o medo de não entender né, também tem isso, e aí eu consegui encontrar um lugar muito rizomático pra essa peça, e aí eu achava que valia a pena enfrentar as estruturas propondo uma coisa, e a experimentação teve mais a ver com o discurso mesmo, do que com o som em si e isso foi muito claro pras pessoas, porque as pessoas me deram feedbacks impressionantes e todos relacionados à surpresa, sobretudo surpresa.

\section{Referências}

BOURRIAUD, N. Relational aesthetics. Nachdr. Dijon: Presses du réel. (Documents sur l'art). 2009. 125 p. (Obra Completa)

CHAVES, R. Nendú: um possível arquivo de arte sonora brasileira realizado entre 20152018. Disponível em: <http://www.nendu.net/?page_id=443\&lang=pt>. Acesso em: 21 abr. 2020. 2015-2018 (Recurso Online) 
CHAVES, R; IAZZETTA, F. (Orgs.). Making it Heard: A History of Brazilian Sound Art. New York: Bloomsbury Academic, 2019. 274 p. (Obra Completa).

DE MICHELIS, V. [auto-residência] Dia 1 - TPM anti-criativa. Disponível em:

<http://humanifestation.blogspot.com/2016/07/auto-residencia-dia-1-tpm-anti-criativa.html>. Acesso em: 21 abr. 2020. 2016. (Recurso Online)

DE MICHELIS, V. Montagem de Palco p/ Mulheres - Sound Stage Setup for Women. .

Disponível em: <https://vimeo.com/118425650>. Acesso em: 4 maio 2020. 2015a. (Recurso Online)

DE MICHELIS, V. Red Bull Contemporary Arts São Paulo-Residency. Disponível em: <https://vimeo.com/141198510>. Acesso em: 4 maio 2020. 2015b. (Recurso Online)

DE MICHELIS, V. Gesto Sonoro - Sound Gesture (Performance / Video Installation). Disponível em: <https://vimeo.com/128100096>. Acesso em: 4 maio 2020. 2015c. (Recurso Online

DE MICHELIS, V. caminhada sonora final. [s.l.: s.n.]. Disponível em: <https://vimeo.com/44948071>. Acesso em: 4 maio 2020. 2011 (Recurso Online)

GONTIJO, J. Distopias tecnológicas. Rio de Janeiro: Editora Circuito, 2014. 224 p. (Obra Completa)

GUATTARI, F. Molecular revolution: psychiatry and politics. Harmondsworth, Middlesex, England; New York, N.Y., U.S.A: Penguin. (Peregrine books). 1984. 308 p. (Obra Completa)

IBRASOTOPE. FIME - Festival Internacional de Música Experimental: vídeo-resumo. Disponível em: 〈https:/www.youtube.com/watch?v=T8Lp1WUgMOE>. Acesso em: 4 maio 2020. 2015. (Recurso Online)

KANDINSKY, Wassily. Ponto e linha sobre plano. Edição: 2. [s.1.]: WMF Martins Fontes POD, 2012. (Obra Completa)

MARTINA, Brunella. A Tensão. 2015. (Fotografia)

NEIVA, T. Engaged Sonorities: Politics and Gender in the Work of Vanessa de Michelis em Making it Heard: A History of Brazilian Sound Art; CHAVES, R., IAZZETTA, F. (Orgs.). New York: Bloomsbury Academic, 2019, p. 229-248. (Capítulo em Livro).

REYNER, Igor Reis. Pierre Schaeffer e sua teoria da escuta. OPUS, v. 17, n. 2, p. 77-106, 2011. (Artigo em periódico digital)

SANNA, G. Interlúdio. [s.1.: s.n.], Disponível em: 〈https://vimeo.com/189941176>. Acesso em: 21 abr. 2020. 2016. (Filme)

SMALL, C. Musicking: the meanings of performing and listening. Hanover: University Press of New England, 1998. 230 p. (Obra Completa)

S/A. Sobre Privilégios. Fonte: Cortesia do acervo Redbull. 2015 (Fotografia) 